\title{
Workplace Romances: Should Individuals Engage in Them or Should Individuals Try to Avoid Them?
}

\author{
Sydney Dechamplain ${ }^{1}$
}

\begin{abstract}
The objective of this paper is to explore workplace relationships and conclude whether individuals should engage in workplace romances (WRs) or whether individuals should try and avoid them. Since individuals spend so much time at the workplace, the likelihood of individuals engaging in a WR is high. Nowadays, there are not many jobs that put restrictions on whether or not you can date or have a relationship with someone you work with, however, is this a problem? Should there be restrictions in place regarding dating coworkers or bosses for example? The findings suggest that even though there are some benefits to WRs, the majority of results show that WRs are dangerous as they can cause group dysfunctions, make other workers uncomfortable, affect team performance, ruin professional relationships, result in sexual harassment claims, and so much more. This paper is going to examine the effects of WRs at different hierarchical levels and whether favoritism or a conflict of interest is present. It is going to examine the effect of WRs on job productivity, morale, and privacy, as well as explore the effects WRs have on other coworkers and what happens when WRs end. Lastly, this paper will explore the question: should management step in when it comes to WRs?
\end{abstract}

\footnotetext{
${ }^{1}$ MacEwan University
} 


\section{Introduction}

Workplace romances (WRs) are "mutually desired romantic relationships between two or more people at work" (Foley \& Powell, 1999, p. 1043). Typically, there exists some elements of "sexuality or physical intimacy" (Foley \& Powell, 1999, p. 1043). WRs are a common behaviour in organizations (Cole, 2009), existing more regularly in the more recent years and affecting how the participants conduct themselves in their work roles (Foley \& Powell, 1999). According to Peirce et al. (2000), "seventy-one percent of employees have either observed or participated in a workplace romance" (Peirce et al., 2000, p. 869), which isn't shocking since more and more individuals are spending lots of time in the workplace (Cole, 2009). Traditionally, WRs were seen as inappropriate in the workplace and were often managed through a disciplinary process (Cole, 2009). Although, as time has passed, WRs have come to be an accepted part of the work life (Cole, 2009). Today, there are surveys which indicate that some workers do not see WRs as "inherently problematic" (Cole, 2009, p. 363), and therefore believe that WRs should not be any of the company's business (Cole, 2009).

On the other hand, WRs have been reported having negative effects on companies' dynamics and team performance. It is said that WRs are likely to affect the work environment of coworkers; Foley and Powell (1999) found that there is a "substantial [amount of] gossip among coworkers" (p. 1043), in regards to WRs. WRs can cause a decline in work performance, as they can have a negative effect on co-worker morale and productivity (Foley \& Powell, 1999). WRs can also ruin professional relationships, threaten career advancement, create co-worker confusion (Cole, 2009), as well as create some inequalities through things like conflicts of interest and biased decision making (Balaban, 2019). In addition, there are issues that arise when a supervisor and subordinate are romantically involved (Foley \& Powell, 1999). According to Darks (2000), "trying to date a co-worker is never a good situation" (para. 4). Even though there are some benefits to WRs, the risks/negative effects outweigh them, and, therefore, individuals should try to steer clear of WRs.

\section{Overview of WRs}

The workplace is the perfect place to meet your true love (Gale, 2012). Workplace romances (WRs) can take many forms. They can form from "a variety of conditions including physical attraction, intellectual attraction, shared energy levels, increased self-esteem from success as a team or two, and the forbidden nature of WR in some workplaces" (Cole, 2009, p. 364). According to Quinn \& Lees (1984), "it is natural for romantic relationships to emerge at work" (Quinn \& Lees, 1984, p. 37). "Relationships at work are inevitable, being a natural aspect that might happen when two [people] work many hours together and have a lot of things in common" (Balaban, 2019, p. 131). WRs have the opportunity to grow and develop since coworkers spend lots of time together and can often have lots in common (Cole, 2009). Individuals spend lots of hours at their workplace surrounded by other individuals. Individuals engage with others through things like "meetings, corporate retreats, business, travel and entertainment" (Cole, 2009, p. 364), etc. Spending all this time together allows individuals to get to know one another in many different ways, allowing them to possibly form a WR. Foley \& Powell (1999) indicate three reasons why individuals might engage in a WR. They are as follows: "love (e.g., sincere love, companionship, spouse), ego (e.g., excitement, ego satisfaction, sexual experience), and job (e.g., advancements, 
security, power, finical rewards)" (Foley \& Powell, 1999, p. 1048). Typically, individuals see a love motive as being appropriate, sincerer and genuine, while they see an ego or job-related motive as being inappropriate, deceitful and fictitious (Pierce et al., 2000). It is also argued that individuals can seem more attractive if they have a larger power position in the workplace; "power can be a stimulator for intimacy" (Quinn \& Lees, 1984, p. 36-37). WRs are not typically a private affair, since most couples who work together are unsuccessful at keeping their romance hidden (Foley \& Powell, 1999). Balaban stated that " $61 \%$ of organizations did not have a policy on office dating" (Balaban, 2019, p. 130). There are lots of companies that do not have any policies regarding WRs, but, when WR activity is producing problems in the workplace, employees get punished for it (Cole, 2009). WRs have their ups and down. They are certainly not a simple matter and, when sex is involved, they become even more complicated (Hollan, 2007).

\section{Benefits to WRs}

With work consuming lots of individuals' time, it can be challenging for them to meet new people outside of the workplace, therefore, the workplace can be that institution that allows individuals to meet and connect with people who may share similar interests. According to Cole (2009), WRs can be an extremely "positive force" as it can improve "the motivation and mental energy of the two parties involved" (p. 364). As a result, this can lead to those individuals working harder and longer, to try to be the best, reaching "self-actualization beyond the limits of their existing relationships" (p. 364). Research has indicated that WRs can occasionally have an enhancing effect on job productivity; Balaban (2019) explained that some couples involved in WRs do become more productive. WRs can improve teamwork, by enhancing communication and cooperation (Cole, 2009). Foley \& Powell (1999) noted that WRs sporadically improved work group functioning "through lowered tensions and improved coordination, teamwork and work flow" (p. 1047). There is some research which indicates that workplace/employee morale employee mood - can be raised (Balaban, 2019). "34\% of the executive women surveyed by Mainiero (1989) reported that a workplace romance can energize employee morale" (Balaban, 2019, p. 130). "WRs can boost workplace morale, inspire other employees, [and] encourage creativity and innovation" (Cole, 2009, p. 364). It is said that individuals who are involved in WRs are both happier and are easier to get along with and, because of this, there is a decrease in personality conflicts around the workplace (Cole, 2009). WRs can also "enrich personal relationships for the couple involved and their coworkers and stabilize the workforce by retaining both partners" (Cole, 2009, p. 364). WRs can also affect co-workers positively, meaning that the work of other employees may improve. For example, some co-workers may work in a more productive manner, with more interest in their role, and with more enthusiasm (Cole, 2009).

\section{Negative Outcomes of WRs}

There are some risks when it comes to WRs. Research revealed that even some of the benefits of WRs listed above can be flipped around and can be seen as negative aspects of WRs. In fact, lots of these characteristics were predominantly seen as more of a negative aspect of WRs than of a positive one. For example, even though some research indicates that employee morale can be raised because of WRs, there is also research which indicates that employee morale can be 
lowered because of WRs (Balaban, 2019). WRs have the possibility to threaten career development; they can wreck professional relationships and can cause individuals work performance to decline (Cole, 2009). WRs can also "lead to self-doubt and lost objectivity on the part of the couple" (Cole, 2009, p. 364). They can generate competition and conflict, as well as produce confusion between co-workers (Cole, 2009). In most cases, WRs, according to Foley \& Powell (1999), were described by "negative work group outcomes such as high levels of gossip, complaints, hostilities, distorted communications, lower morale, and lower productivity" (Foley \& Powell, 1999, p. 1047).

\section{Job Productivity}

Job productivity is a risk to WRs. Companies are concerned whether or not WRs affect job productivity (Balaban, 2019). Research has indicated that WRs can occasionally have "an impending effect on job productivity" (Balaban, 2019, p. 129). Balaban (2019) notes that "newly formed couples are initially less productive because of large amounts of time and energy invested in their relationship" (Balaban, 2019, p. 129). When individuals first engage in new relationships, they spend lots of their time with that person, trying to develop and grow their relationship. Often people put other things on the backburner, making their relationships their sole focus. Balaban (2019) continues to say that, "in the early stages of workplace romance when couples admit their mutual sexual attraction and proceed toward one another, productivity may decline" (Balaban, 2019, p. 129). When individuals engage in WRs they are more likely to show up to work late or leave work early; they are also more likely to be late or miss meetings, which results in a decline in productivity (Balaban, 2019). Overall, lots of research indicates that "job productivity can be negatively affected by workplace liaisons" (Balaban, 2019, p. 129).

\section{Hierarchical Levels}

When individuals date people at different hierarchical levels, power structures in organizations are disrupted (Cole, 2009). As a result, this produces exceptionally "high-risk situations and professional [conflicts] of interest" (Cole, 2009, p. 364). WRs between individuals at different ranks produce strongly negative responses (Foley \& Powell, 1999). According to Pierce et al. (2000), "24 percent of managers have been romantically involved with an office colleague at least once" (Pierce et al., 2000, p. 869). Research indicates that WRs between a supervisor and subordinate are often perceived more negatively than WRs between workers at the same rank (Pierce et al., 2000). Some co-workers "view the subordinate as not freely choosing to engage in the romance due to the power differential" (Foley \& Powell, 1999, p. 1048). Some may view the WR as the individual higher up forcing themselves on the individual in the lower position (Foley \& Powell, 1999). Bosses or supervisors can intimidate employees unintentionally (Darks, 2000, para 3). Therefore, if they are trying to pursue a relationship with an employee at a lower level, they might actually be intimidating them into the said relationship (Darks, 2000, para 3). WRs can also affect mentoring relationships, "create the possibility of retaliatory sexual harassment allegations, and block advancements for the subordinate when it ends badly" (Cole, 2009 , p. 364). "In some situations, such as when supervisors and subordinates are romantically involved with one another, WRs also have a negative effect on co-worker morale and productivity" 
(Foley \& Powell, 1999, p. 1044). Some co-workers may assume that individuals receive task and career rewards, like preferred assignments or promotions, when they take part in WRs involving different hierarchical levels (Foley \& Powell, 1999). When a WR involves two individuals at different ranks - a superior and a subordinate - "the superior may use the personal relationship to force increased task performance, and the subordinate may use the personal relationship to demand favorable task assignments" (Foley \& Powell, 1999, p. 1044). Sometimes one of the participants in a WR may manipulate the other into doing what they want (Foley \& Powell, 1999). In a WR one of the participants may "[exploit] the other by taking advantage of the other's dependency on the personal relationship" (Foley \& Powell, 1999, p. 1044). As a result of this, the group's work performance would very commonly be disrupted (Foley \& Powell, 1999, p. 1044). "Experts say companies should institute office dating policies, especially when it comes to managers dating subordinates" (Gale, 2012, para 1).

\section{Favouritism}

According to Peirce et al. (2000), there are several reasons as to why employees view WRs involving a supervisor and subordinate negatively. There is "jealously and suspicion regarding favoritism in terms of pay, promotions, workload, and vacation time" (Peirce et al., 2000, p. 870). When WRs develop, behavioural changes occur between the individuals involved in the WR (Quinn \& Lees, 1984). Typically, favoritism between the couple exists, no matter the hierarchical status of the participants involved (Quinn \& Lees, 1984). Co-workers are generally concerned that when WRs develop, individuals involved will display favoritism, as well as offer "employment benefits to each other not given to other co-workers" (Balaban, 2019, p. 128). Supervisorsubordinate relationships have a certain disruptive effect on work groups because of the fear that coworkers face in regards to favoritism, which results from the unavoidable conflict of interest that WRs create (Foley \& Powell, 1999). "Jealously and suspicion may stem from the fact that hierarchical romances often involve a social power differential whereby the higher-status participant has the ability to influence - perhaps inappropriately - the lower-status participant" (Peirce et al., 2000, p. 870). "Mainiero (1989) conceded that hierarchical romances can be devastating and destructive because of the jealousy and suspicion regarding favouritism" (Balaban, 2019, p. 130).

\section{Morale}

According to Balaban (2019), WRs can have an effect on "employee morale" (Balaban, 2019 , p. 130), meaning that "the mood or spirit of the work group can be influenced by romantic organizational behaviour" (Balaban, 2019, p. 130). The case that tends to disrupt employee morale the most is WRs involving two individuals at different ranks (Balaban, 2019). WRs involving individuals at different hierarchical levels typically have a negative effect on the moral of coworkers; for example, if the "subordinate is perceived to be receiving preferential treatment" (Cole, 2009, p. 364), other workers will be upset. Balaban (2019) stated that "[group] morale can be negatively affected as the result of a romantic dependency that exists in a boss-subordinate liaison" (Balaban, 2019, p. 130), which regards the issues with hierarchical romances and unequal social power (Balaban, 2019). This causes more of a disruption than WRs involving individuals at the 
same rank. According to Foley \& Powell (1999), WRs between superiors and subordinates were noted to have a negative effect on coworker morale, while WRs between individuals at the same ranks were noted to have a positive effect on morale.

\section{Effect on Coworkers}

WRs are typically not something that individuals can keep hidden from other workers. That being said, WRs promote "interesting topics of discussion among organizational members" (Balaban, 2019, p. 130). Cole (2009) found that individuals who were married, but involved in a WR, made co-workers feel tremendously uncomfortable, especially if those individuals knew the spouse. "Employees who are perceived as being romantically involved with other organizational members because of job-related motives are more likely to create negative gossip" (Balaban, 2019, p. 130), compared to "employees who are perceived as being romantically involved with other organizational members because of love motives" (Balaban, 2019, p. 130). When co-workers notice WRs to be unfair, they typically expect management to jump in and intervene, however "managerial inaction is the most likely response" (Foley \& Powell, 1999, p. 1044). Some coworkers view WRs as a "coalition that has unfairly altered the balance of power in the organization" (Foley \& Powell, 1999, p. 1047). "Coworkers' responses to WRs vary from approval to tolerance to outright objection expressed to the participants or to the management" (Foley \& Powell, 1999, p. 1047). Coworkers speak up and object when participants in a WR seem to have "gained an unfair advantage in the workplace in exchange for satisfying the other participant's desire for ego gratification" (Foley \& Powell, 1999, p. 1048). Co-workers are influenced by the perception and impact that WRs have on the work environment and their preference for outcomes stems from this (Foley \& Powell, 1999). This is things like whether or not there is a conflict of interest present for the individuals involved in the WR, or whether or not the WR disrupts the way the work group functions (Foley \& Powell, 1999).

\section{Conflict of Interest}

Foley \& Powell (1999) states that "perceptions of conflict of interest arise when individuals have the capability of advancing their own personal interest or the interest of others with whom they are personally involved through their official status or actions" (Foley \& Powell, 1999, p. 1046). Coworkers are likely to perceive a conflict of interest when they believe that there is a connection between an individual's work performance and the rewards they receive (Foley \& Powell, 1999). They are also likely to perceive a conflict of interest when they "believe that the WR has led or will lead to the sharing of confidential information during 'pillow talk' that otherwise would not be shared, thereby giving both participants an unfair advantage over nonparticipants" (Foley \& Powell, 1999, p. 1046-1047). WRs that result in conflicts of interest are prone to disturb the functioning of the work group because they "violate coworkers' sense of justice in the workplace" (Foley \& Powell, 1999, p. 1047). "When co-workers become romantically involved with each other, a personal domain is added that cannot be reached by other co-workers" (Balaban, 2019, p. 128). As a result, this can cause complications within the work group, and the complications are even more severe when participants are of different organizational statuses (Balaban, 2019). This can create a "power imbalance" (Balaban, 2019, p. 
128), and, if a power imbalance exists, then "the exploitation and work group dysfunction may also exist" (Balaban, 2019, p. 128).

\section{Breakups}

When couples break up, it can create challenging problems for their employers (Gale, 2012). "Workplace romance may result in conflicts of interest, biased decision making and other inequalities that negatively affect the performance, should the romance terminate" (Balaban, 2019, p. 128). Unfortunately, there are some relationships that just do not make it; people can fall into love as well as out of love. When WRs end, there are naturally more issues that can occur, compared to relationships with other individuals not in the workplace. If couples do not last, breakups can result in anger, hatred, bitterness, etc. throughout the workplace (Cole, 2009). As a result, WRs that are over can lead to a disruption and mayhem in the workplace (Cole, 2009). Sadly, WRs can go "sour" (Balaban, 2019, p. 130) and, as a result, one of the individuals in the relationship may "[retaliate] with a sexual harassment claim" (Balaban, 2019, p. 130).

\section{Sexual Harassment}

Sexuality can present itself in many different forms in the workplace (Balaban, 2019). Sexuality has "multiple and contradictory meanings and consequences" (Balaban, 2019, p. 134). "Sexual harassment is the most easily defined type of sexual behaviour at work" (Quinn \& Lees, 1984, p. 41). As a result of a dissolved WR, sexual harassment can occur (Cole, 2009). Darks (2000) states that “[often] today's romance is tomorrow's sexual harassment case - especially when the relationship is between a supervisor and a subordinate" (para. 4). He continues to say that "even if both parties seem to be getting along fine, things can go sour if one partner breaks it off" (Darks, 2000, para. 4); "suddenly a love affair can turn into a claim of harassment" (Darks, 2000, para. 4). Balaban (2019) notes that $42 \%$ of female workers claimed they had had at least one experience of sexual harassment, whereas only $15 \%$ of male workers claimed they had had at least one experience of sexual harassment (Balaban, 2019, p. 130). According to Balaban (2019), some organizations may feel the need to ban WRs because of the possible risk of sexual harassment. Companies will spend approximately 8 million dollars per year on sexual harassment claims (Balaban, 2019). As a result of sexual harassment claims, companies can be affected poorly, with some of the damages including "lost productivity, resignations, and decreased morale" (Balaban, 2019 , p. 130). There is a mixed amount of research that display that "organizations attempt to control and to monitor sexual behaviour among workers, but also that workers resist and negotiate these constraints" (Balaban, 2019, p. 134). Here, WRs can put employers - the management team - in a predicament (Balaban, 2019, p. 130). On the one hand, if "a supervisor intervenes prematurely, the company [can face] the liability of a privacy lawsuit" (Balaban, 2019, p. 130). However, on the other hand, "if a company ignores a workplace romance that ends in a sexual harassment claim, [the company] is potentially liable" (Balaban, 2019, p. 130). According to Darks (2000), some companies have prohibited employees from engaging in WRs with anyone who is below them in their hierarchical status (Darks, 2000, para. 9). 


\section{Should Management Intervene?}

"Over 70\% of organizations do not have formal WR polices" (Cole, 2009, p. 364). In most workplaces, there are unwritten rules and regulations between employees and the HR management, in regards to hierarchical WRs not being seen as a wise choice (Cole, 2009). Even though many companies do not forbid WRs, Gale (2012) argues that companies should create some rules and regulations around what is exactly "allowed-or risk being surprised by what workers think is acceptable" (Gale, 2012, para. 4). Typically, HR managers always have an eye out for WRs, but they do not intrude into the relationship unless the relationship creates "dysfunctional results such as performance decline or violation of company policies (Cole, 2009, p. 364). According to Balaban (2019) "workplace romances should not be of managerial concern unless they disrupt an employee's performance" (Balaban, 2019, p. 129). Since any type of relationship can have its ups and downs, Balaban (2019) believes that WRs should not be ignored and that organizations should put in place a defence plan - policy and procedures - for handling the unfortunate negative outcomes in regards to WRs. Managers should not ignore WRs because of the significant effects and consequences they can have on other workers and the organization in general (Balaban, 2019).

If managerial action needs to be taken then it is important to assess fairness when it comes to managerial action (Cole, 2009). Cole (2009) talks about how in situations where co-workers' performances are negatively affected by a WR, or where the work environment is negatively affected by a WR, management should step in, and how it is fair for them to do so. Managers are more likely to respond to a WR in a positive manner if the WR does not affect other co-workers, or the company in general (Balaban, 2019). They may also respond more positively if the job performance of the individuals involved in the WR is not affected negatively, if the individuals involved in the WR continue to act professionally, and if the individuals involved in the WR are happier overall (Balaban, 2019). If WRs have negative effects on other workers or the workplace, managers may make the executive decision to relocate one of the individuals involved in the relationship (Balaban, 2019). A more harmful and punitive decision that managers may make would be to "terminate or dismiss an employee because of his or her involvement in a workplace relationship" (Balaban, 2019, p. 133). Foley \& Powell (1999) note that WRs which involved participants at a 'lower-level' were more likely to result in them being relocated or terminated compared to participants at a 'higher-level' (Foley \& Powell, 1999, p. 1044).

\section{Privacy}

When it comes to WRs, the couples' privacy is something that might be intruded. Since WRs are not typically private affairs, meaning that most employees know when individuals are engaging in a WR, other workers can be interested in all the details about that WR. Individuals can be nosy. They can be interested in the ups and downs of that WR. Balaban (2019) states that "a co-worker to co-worker relationship has the greatest rights to privacy and employers have fewer rights to intervene unless the relationship affects performance or ends in a sexual harassment [claims]" (Balaban, 2019, p. 133). On the other hand, "in a supervisor to subordinate relationship the supervisor has fewer rights and the employers have more rights to intervene because both the company and supervisor are exposed to sexual harassment claims... and can be perceived as a conflict of interest by other co-workers" (Balaban, 2019, p. 133). 


\section{Conclusion}

WRs can affect an organization either positively or negatively (Balaban, 2019). Cole (2009) reported that the "purported benefits of WR are rarely realized or at least rarely perceived by coworkers" (Cole, 2009, p. 370). Lots of research highlights the negative impacts, rather than positive impacts, of WRs on the individuals involved in the relationship, as well as on the managers and the organization as a whole (Balaban, 2019). This is because, even though there are some benefits to WRs, the risks and negative outcomes of them are more prevalent and more harmful. There are times that WRs may be inevitable; two individuals may connect on a different level and may be each other's true loves, but because of the negative outcomes and risks that WRs create, individuals should try and avoid WR if possible. 


\section{References}

Balaban, R. V. (2019). Romance at Work and the Negative Impact It Has on the Workplace Environment. Journal of Public Administration, Finance \& Law, 15, 127-134.

Cole, N. (2009). Workplace Romance: A Justice Analysis. Journal of Business \& Psychology, 24(4), 363-372. https://doi.org/10.1007/s10869-009-9117-1

Darks, M. C. (2000). When You're in Charge and in Love. Business News New Jersey, 13(43), 21.

Foley, S. \& Powell, N. G. (1999). Not All Is Fair in Love and Work: Coworkers' Preferences for and Responses to Managerial Interventions regarding Workplace Romances. Journal of Organizational Behavior, 20(7), 1043.

Gale, S. F. (2012). Love Takes Work, but Can Work Take Love? Workforce Management, 91(10), 10.

Hollon, J. (2007). Bad breakup. Workforce Management, 86(21), 58.

Pierce A. C., Aguinis H., \& Adams K. R. S. (2000). Effects of a Dissolved Workplace Romance and Rater Characteristics on Responses to a Sexual Harassment Accusation. The Academy of Management Journal, 43(5), 869-880.

Quinn, R. E., \& Lees, P. E. (1984). Attraction and Harassment: Dynamics of Sexual Politics in the Workplace. Organizational Dynamics, 13(2), 35-46. https://doi.org/10.1016/00902616(84)90017-2 